\title{
THE EFFECT OF A PORTACAVAL SHUNT ON ESTIMATED HEPATIC BLOOD FLOW AND OXYGEN UPTAKE IN CIRRHOSIS ${ }^{1}$
}

\author{
By S. E. BRADLEY, C. M. SMYTHE, ${ }^{2}$ H. F. FITZPATRICK, AND A. H. BLAKEMORE \\ WITH THE ASSISTANCE OF A. I. S. MACPHERSON ${ }^{8}$ AND A. GAMMELTOFT 4 \\ (From the Departments of Medicine and Surgery, Columbia University College of Physicians \\ and Surgeons, and the Presbyterian Hospital, New York, N. Y.)
}

(Submitted for publication January 19, 1953; accepted March 4, 1953)

Analysis of hepatic hemodynamic adjustments is made peculiarly difficult by the complexity of the splanchnic circulation. Blood flow through the liver appears to be controlled by the interactions between four sets of vascular resistances: (a) those imposed between the aorta and the portal vein including the splenic, gastric, mesenteric, and colic arterioles; (b) those between the aorta and the sinusoids, the hepatic arterioles; (c) those between the portal vein and the sinusoids, the portal venules; and (d) those between the sinusoids and the hepatic veins. During the development of cirrhotic disease of the liver a fifth set of resistances between the portal vein and the inferior vena cava, i.e., the collateral circulation, becomes important in determining blood flow. The portal venous pressure and the sinusoidal pressure are, likewise, resultants of the interaction of these resistances and arterial pressure. A change in any one resistance alone will induce various changes in the rate of blood flow through all the others and will affect the pressures in both the portal vein and sinusoids. In the absence of quantitative data regarding these factors, therefore, any discussion of the dynamics of splanchnic flows and pressures must be guarded. Nevertheless, it has seemed reasonable to believe that portal hypertension develops during cirrhotic disease (initially, at least) as a result of increased resistance to portal venous flow into the liver. Hence the reduction in hepatic blood flow

1 This work was supported by a grant from the New York Heart Association. Preliminary reports have appeared in abstract form $(1,2)$.

2 Fellow of the American College of Physicians. Present address: Naval Medical Field Laboratory, Camp Lejeune, North Carolina.

8 Visiting Scholar in Surgery. Present address : Dept. of Surgery, University of Edinburgh, Edinburgh, Scotland.

4 Visiting Scholar in Surgery. Present address : Amaliegade 39, Copenhagen K, Denmark. demonstrable under these circumstances is presumably to some extent a measure of the reduction in portal venous inflow. The fact that the hepatic venous oxygen content is reduced in cirrhosis (3) suggests further that the portal venous blood provides a substantial portion of the oxygen supply to the liver in man.

Although these views may not be subjected to experimental evaluation in human subjects, the recent development of effective surgical procedures for the treatment of portal hypertension offers an alternative approach. Portacaval or splenorenal venous anastomosis permits the escape of blood from the engorged portal vein into the systemic venous system and lowers portal venous pressure $(4,5)$. The resulting reduction in portal inflow should reproduce or exaggerate the hepatic hemodynamic changes of cirrhosis mentioned above if these are due to portal venous obstruction. In addition, it is possible to determine the oxygen content of portal venous blood withdrawn several days post-operatively through a catheter left in place to permit local infusion of heparin. Measurements of hepatic blood flow and oxygen uptake were therefore made before and after portacaval anastomosis in patients with cirrhosis of the liver.

\section{METHODS}

The subjects of this study were 12 patients with wellestablished portal hypertension and cirrhosis of the liver. Eleven had suffered repeated blood loss from ruptured esophageal varices and one presented herself with intractable ascites which had failed to respond to prolonged medical management. In all, biopsies of the liver provided definite evidence of cirrhosis. A resumé of the more important data obtained in the clinical study of each patient is appended (Addenda). A history of excessive alcohol intake was obtained in only two individuals (T. K. and E. K.). In seven (K. N., P. P., C. M., N. D., A. R., K. O'D., and S. W.) it seemed likely that the cirrhotic process had its inception in some variety of hepa- 
TABLE I

The effect of portacaval anastomosis upon estimated hepatic blood flow*

\begin{tabular}{|c|c|c|c|c|c|c|c|c|c|c|c|c|}
\hline \multirow[b]{2}{*}{ Subject } & \multicolumn{6}{|c|}{ Pre-operative } & \multicolumn{6}{|c|}{ Post-operative } \\
\hline & PBSP & $\Delta \mathbf{P}$ & $\mathbf{E}_{\mathrm{BBP}}$ & $\mathbf{R}_{\text {B8P }}$ & $\underset{\text { crit }}{\text { Hemato- }}$ & EHBF & $\mathbf{P}_{\text {BgP }}$ & $\Delta \mathbf{P}$ & $\mathbf{E}_{\mathbf{B S P}}$ & RBBP & $\underset{\text { crit }}{\text { Hemato- }}$ & EHBF \\
\hline $\begin{array}{l}\text { A. R. } \\
\text { P. P. } \\
\text { K. N. } \\
\text { P. McC. } \\
\text { P. N. } \\
\text { N. D. } \\
\text { S. W. } \\
\text { H. C. } \\
\text { T. K. } \\
\text { E. K. }\end{array}$ & $\begin{array}{c}m g . \% \\
1.28 \\
1.49 \\
1.85 \\
1.32 \\
1.50 \\
1.33 \\
0.83 \\
0.63 \\
0.83 \\
0.77\end{array}$ & $\begin{array}{r}\text { mg. } \% 1 \\
\text { min. } \\
+0.005 \\
000 \\
+0.030 \\
+0.002 \\
+0.040 \\
+0.005 \\
+0.001 \\
+0.001 \\
+0.010 \\
+0.030\end{array}$ & $\begin{array}{c}\% \\
26.0 \\
11.5 \\
12.0 \\
32.0 \\
11.0 \\
34.0 \\
26.0 \\
45.0 \\
42.0 \\
25.0\end{array}$ & $\begin{array}{l}\text { mg. } \\
\min . \\
2.0 \\
1.1 \\
1.4 \\
2.5 \\
1.3 \\
3.4 \\
1.7 \\
2.3 \\
3.5 \\
1.8\end{array}$ & $\begin{array}{c}\% \\
36.0 \\
35.0 \\
40.0 \\
42.0 \\
36.0 \\
44.0 \\
41.0 \\
39.0 \\
41.0 \\
47.0\end{array}$ & $\begin{array}{c}\text { ml. } / \text { min. } \\
940 \\
960 \\
1,030 \\
1,030 \\
1,220 \\
1,310 \\
1,330 \\
1,340 \\
1,720 \\
1,780\end{array}$ & $\begin{array}{c}\text { mg. \% } \\
1.85 \\
1.44 \\
1.32 \\
1.34 \\
0.81 \\
1.30 \\
0.88 \\
0.87 \\
0.70 \\
1.55\end{array}$ & $\begin{array}{c}\text { mg. \%l } \\
\text { min. } \\
-0.010 \\
+0.008 \\
+0.005 \\
+0.005 \\
-0.006 \\
+0.001 \\
-0.005 \\
-0.001 \\
+0.008 \\
+0.001\end{array}$ & $\begin{array}{c}\% \\
45.0 \\
38.0 \\
38.0 \\
37.0 \\
47.0 \\
37.0 \\
57.0 \\
71.0 \\
36.0 \\
23.0\end{array}$ & $\begin{array}{l}\text { mg.l } \\
\text { min. } \\
2.5 \\
2.2 \\
2.7 \\
1.9 \\
2.0 \\
2.9 \\
1.7 \\
2.7 \\
2.1 \\
2.2\end{array}$ & $\begin{array}{c}\% \\
37.0 \\
43.0 \\
43.0 \\
40.0 \\
45.0 \\
40.0 \\
31.0 \\
43.0 \\
44.0 \\
35.0\end{array}$ & $\begin{array}{r}\text { ml. } / \text { min } \\
480 \\
710 \\
940 \\
630 \\
960 \\
1,030 \\
500 \\
760 \\
1,490 \\
950\end{array}$ \\
\hline $\begin{array}{c}\text { Mean } \\
\sigma\end{array}$ & & & $\begin{array}{r}26.5 \\
\pm 12.9\end{array}$ & & & $\begin{array}{l}1,266 \\
\pm 282\end{array}$ & & & $\begin{array}{r}42.9 \\
\pm 12.5\end{array}$ & & & $\begin{array}{r}845 \\
\pm 284\end{array}$ \\
\hline
\end{tabular}

* Abbreviations are as follows: $\mathrm{P}_{\mathrm{BgP}}=$ plasma level of bromsulfalein (BSP); $\Delta \mathrm{P}=$ change in plasma level of $\mathrm{BSP}$; $\mathrm{E}_{\mathrm{BsP}}=$ hepatic extraction of BSP (difference between BSP concentration in peripheral arterial and hepatic venous blood divided by concentration in arterial blood); $\mathbf{R}_{\mathrm{BSP}}=$ rate of disappearance of $\mathrm{BSP}$ from the blood (taken as hepatic removal rate); and $\mathrm{EHBF}=$ estimated hepatic blood flow.

titis. Disease of the biliary tract may have been important in two of these, (K. N. and P. P.). In the remainder, the cause of cirrhosis and portal venous hypertension was uncertain. Extra-hepatic portal venous obstruction may have played a role in $\mathrm{P}$. $\mathrm{N}$. and $\mathrm{P}$. McC. In the latter, however, the portal venous thrombosis encountered at the time of portacaval anastomosis may have developed as a result of an earlier splenectomy. The changes in liver function ranged widely and showed no consistent pattern in the group as a whole. In five patients (P. N., P. P., T. K., K. N., and H. C.) the spleen was removed and an end-to-side anastomosis established between the splenic vein and the left renal vein. The portal vein and the inferior vena cava were united in three ( $P$. McC., N. D., and E. K.) by an end-to-side anastomosis and in two (A. R. and S. W.) by a side-to-side anastomosis. At the time of operation the shunt functioned efficiently in all and it appeared to be patent at the time of study following operation with one possible exception (K. O'D.). The term "portacaval anastomosis" will be used throughout this paper as a general expression indicating any one of these three shunting operations. All subjects were fasting and resting quietly in recumbency at the time of study from one to 80 days preoperatively and within less than six weeks post-operatively in 10 , seven months in one (K. O'D.) and 30 months in another (K. N.) (see Addenda).

The hepatic blood flow (EHBF) was estimated by the bromsulfalein (BSP) method (6) in 10 of the 12 patients before and after operation. For this purpose an infusion of BSP was administered intravenously at a rate maintained constant by a calibrated Bowman pump ${ }^{5}$ and ad-

\footnotetext{
S Obtained from the Process and Instruments Company,
} Brooklyn, N. Y. justed (2.2 mg. per minute on the average) to keep the plasma BSP concentrations below $2.0 \mathrm{mg}$. per cent following injections of a "priming" dose of 100 to $150 \mathrm{mg}$. A venous catheter was introduced into a right hepatic vein under fluoroscopic control and was left in position throughout the study. Thirty to 60 minutes after beginning the BSP infusion, samples of peripheral arterial or venous blood and hepatic venous blood were obtained alternately at $\mathbf{5}$ to $\mathbf{1 0}$ minute intervals. Bromsulfalein concentrations were determined in plasma colorimetrically (6). Hepatic plasma flow was calculated from the values for hepatic BSP removal rate (computed on the basis of the rate. of infusion and the rate of change in peripheral BSP plasma concentrations) and the hepatic arteriovenous BSP plasma concentration difference (6). Since bilirubinemia introduces a variable error in the determination of BSP, patients without jaundice were selected for this study. Only in N. D. and P. P. was the serum bilirubin more than $2.0 \mathrm{mg}$. per cent at the time of any of these measurements. When bromsulfalein extraction (difference between plasma BSP concentrations in hepatic venous and peripheral arterial or venous plasma divided by the concentration in peripheral arterial or venous plasma) was less than 10 per cent at peripheral plasma concentrations greater than $1 \mathrm{mg}$. per cent or less than 15 per cent at peripheral levels below $1 \mathrm{mg}$. per cent, the determinations were considered valueless and discarded. Under these circumstances hepatic arteriovenous difference is too small for accurate measurement. It is for this reason that EHBF could not be determined in $K$. O'D. and C. M. Hepatic blood flow (EHBF) was computed from the values for plasma flow and arterial hematocrits determined using Wintrobe tubes centrifuged at 3,000 r.p.m. for 30 minutes.

Samples of peripheral arterial and hepatic venous blood were obtained simultaneously under anaerobic conditions 
TABLE II

The effect of portacaval anastomosis upon hepatic oxygen metabolism

\begin{tabular}{|c|c|c|c|c|c|c|c|c|c|c|c|c|}
\hline \multirow[b]{3}{*}{ Subject } & \multicolumn{6}{|c|}{ Pre-operative } & \multicolumn{6}{|c|}{ Post-operative } \\
\hline & \multicolumn{2}{|c|}{ Arterial } & \multicolumn{2}{|c|}{ Hepatic venous } & \multirow{2}{*}{$\begin{array}{l}\text { Hepatic } \\
\text { oxygen } \\
\text { A-V dif. }\end{array}$} & \multirow{2}{*}{$\begin{array}{l}\text { Hepatic } \\
\text { oxygen } \\
\text { uptake }\end{array}$} & \multicolumn{2}{|c|}{ Arterial } & \multicolumn{2}{|c|}{ Hepatic venous } & \multirow{2}{*}{$\begin{array}{l}\text { Hepatic } \\
\text { oxygen } \\
\text { A-V dif. }\end{array}$} & \multirow{2}{*}{$\begin{array}{l}\text { Hepatic } \\
\text { oxygen } \\
\text { uptake }\end{array}$} \\
\hline & $\begin{array}{l}\text { Oxygen } \\
\text { content }\end{array}$ & $\begin{array}{c}\text { Oxygen } \\
\text { capacity }\end{array}$ & $\begin{array}{l}\text { Oxygen } \\
\text { content }\end{array}$ & $\begin{array}{c}\text { Oxygen } \\
\text { saturation }\end{array}$ & & & $\begin{array}{l}\text { Oxygen } \\
\text { content }\end{array}$ & $\begin{array}{c}\text { Oxygen } \\
\text { capacity }\end{array}$ & $\begin{array}{l}\text { Oxygen } \\
\text { content }\end{array}$ & $\begin{array}{c}\text { Oxygen } \\
\text { saturation }\end{array}$ & & \\
\hline $\begin{array}{l}\text { A. R. } \\
\text { P. P. } \\
\text { R. N. } \\
\text { P. McC. } \\
\text { P. N. } \\
\text { N. D. } \\
\text { S. W. } \\
\text { H. C. } \\
\text { T. K. } \\
\text { E. K. } \\
\text { C. M. } \\
\text { K. O'D. }\end{array}$ & $\begin{array}{r}m l . \% \\
15.2 \\
13.3 \\
15.9 \\
15.5 \\
15.6 \\
18.6 \\
17.9 \\
14.2 \\
14.7 \\
18.5 \\
14.5 \\
16.5\end{array}$ & $\begin{array}{r}\text { ml. \% } \\
15.9 \\
14.1 \\
17.2 \\
16.3 \\
16.5 \\
19.6 \\
19.6 \\
15.2 \\
15.2 \\
20.6 \\
15.8 \\
17.6\end{array}$ & $\begin{array}{r}m l . \% \\
11.0 \\
8.4 \\
12.5 \\
10.9 \\
11.4 \\
14.1 \\
15.0 \\
10.9 \\
11.0 \\
13.8 \\
10.8 \\
11.4\end{array}$ & $\begin{array}{c}\% \\
69.2 \\
59.5 \\
72.6 \\
67.0 \\
69.0 \\
72.0 \\
76.5 \\
71.8 \\
72.5 \\
67.0 \\
68.5 \\
64.8\end{array}$ & $\begin{array}{c}\text { ml. \% } \\
4.2 \\
4.9 \\
3.4 \\
4.6 \\
4.2 \\
4.5 \\
2.9 \\
3.3 \\
3.7 \\
4.7 \\
3.7 \\
5.1\end{array}$ & $\begin{array}{c}\text { ml./min. } \\
39.5 \\
47.0 \\
35.0 \\
47.4 \\
51.2 \\
-59.0 \\
38.6 \\
44.2 \\
63.7 \\
83.6 \\
- \\
-\end{array}$ & $\begin{array}{c}m l . \% \\
14.7 \\
16.4 \\
16.5 \\
16.6 \\
15.7 \\
17.1 \\
12.8 \\
15.5 \\
15.3 \\
13.3 \\
16.8 \\
16.4\end{array}$ & $\begin{array}{r}m l . \% \\
15.5 \\
18.7 \\
17.5 \\
17.2 \\
16.7 \\
18.1 \\
12.8 \\
16.6 \\
16.5 \\
14.7 \\
20.0 \\
17.2\end{array}$ & $\begin{array}{r}m l . \% \\
8.1 \\
8.0 \\
11.8 \\
7.7 \\
8.9 \\
11.9 \\
6.5 \\
10.5 \\
10.4 \\
9.4 \\
12.3 \\
11.8\end{array}$ & $\begin{array}{l}\% \\
52.2 \\
42.8 \\
67.5 \\
44.6 \\
53.2 \\
66.0 \\
50.8 \\
63.2 \\
63.0 \\
64.0 \\
61.5 \\
68.6\end{array}$ & $\begin{array}{c}\text { ml. \% } \\
6.6 \\
8.4 \\
4.7 \\
8.9 \\
6.8 \\
5.2 \\
6.3 \\
5.0 \\
4.9 \\
3.9 \\
4.5 \\
4.6\end{array}$ & $\begin{array}{c}\text { ml. } / \min . \\
31.6 \\
59.8 \\
44.1 \\
56.1 \\
65.2 \\
53.6 \\
31.5 \\
38.0 \\
73.0 \\
37.0 \\
-\end{array}$ \\
\hline$\underset{\sigma}{\text { Mean }}$ & & & & & $\begin{array}{r}4.1 \\
\pm .6\end{array}$ & $\begin{array}{r}50.9 \\
+13.9\end{array}$ & & & & & $\begin{array}{r}5.8 \\
\pm 1.5\end{array}$ & $\begin{array}{r}48.9 \\
\pm 14.0\end{array}$ \\
\hline
\end{tabular}

for the determination of hepatic oxygen arteriovenous difference in all 12 patients before and after operation. In two of these (E. K. and H. C.) and in eight additional patients ${ }^{\circ}$ a small bore plastic catheter left in the portal vein at operation to permit regional heparinization (7) was used as a route for the withdrawal of portal venous blood anaerobically several days post-operatively. This device permitted determination of portal venous oxygen content (under fasting resting conditions) undisturbed by the effects of surgical manipulation, anesthesia or the administration of oxygen. Arterial blood was obtained simultaneously for the determination of arterial-portal venous oxygen difference. Blood oxygen content and capacity were determined by the method of Van Slyke and Neill (8). The venous oxygen concentrations were corrected, when necessary, for inadvertent dilution by the dextrose ( 5 per cent) or saline solution with which the catheters were perfused to prevent obstruction by clotting. This correction was made on the basis of the arterial oxygen capacities (6).

\section{RESULTS}

The results of these studies are tabulated in Tables I to III. The values necessary for the calculation of estimated hepatic blood flow (EHBFTable I) were taken at the time in each study when the plasma BSP concentration $\left(\mathrm{P}_{\mathbf{B S P}}\right)$ was chang-

- A more detailed account of the clinical status of each of these patients was deemed unnecessary because measurements of hepatic blood flow and oxygen uptake were not made. Each had undergone portacaval anastomosis for the treatment of persistent portal hypertension and was recovering uneventfully at the time of study. ing least (the rate of change is recorded in the Table under $\Delta \mathrm{P}$ ) and $\mathrm{BSP}$ extraction $\left(\mathrm{E}_{\mathrm{BSP}}\right)$ was maximal. The data in the tables are arranged in ascending order according to the pre-operative figures for EHBF (Table I).

\section{Estimated hepatic blood flow}

Estimated hepatic blood flow averaged 1,266 $\mathrm{ml}$. per minute $(\sigma= \pm 282)$ and ranged from 940 to $1,780 \mathrm{ml}$. per minute prior to operation (Table I). It decreased in every instance post-operatively, falling on the average to $845 \pm 284 \mathrm{ml}$. per minute with a range of 480 to $1,490 \mathrm{ml}$. per minute. The difference between the values obtained before and after operation was highly significant, amounting to more than five times the standard error of the difference (relative deviate, dev./S.E., or the ratio between the difference between the means and the standard error of the difference $=5.2$ ). The percentage decrement in EHBF ranged from 9 to 62 per cent. No correlation between this change and the magnitude of the preoperative figure was demonstrable. These data were insufficient to permit accurate evaluation of the type of surgical procedure in terms of its effect on EHBF. However, the largest reductions (S. W., 62 per cent; A. R., 49 per cent) occurred following side-to-side portacaval anastomosis and the smallest following splenorenal venous anastomosis (P. P., K. N., P. N., H. C., and T. K.). 
The change observed in EHBF following portacaval anastomosis appeared to provide a valid measure of the change in hepatic venous outflow. The bromsulfalein clearance method is based on the assumptions (1) that BSP is removed from the blood exclusively by the liver and (2) that the sample of blood taken from the hepatic vein is representative of mixed hepatic venous blood. Studies $(3,9,10)$ of BSP removal in normal animals have revealed that approximately 5 per cent of the total amount removed from the blood in each minute at plasma concentrations of $2 \mathrm{mg}$. per cent or less, can be accounted for by extrahepatic loss. Since there is no reason to suppose that extrahepatic BSP uptake is augmented during liver disease and since the total BSP removal was reduced to approximately one-half normal among the patients studied in this series, it may be inferred that extrahepatic removal accounted for no more than 10 per cent of the total. An error of this magnitude is thus introduced in the calculation of hepatic blood flow. A more serious difficulty arises from the need to take blood from a single hepatic vein. There is insufficient evidence at present to warrant the view that such a sample is fairly representative of all the blood emerging from the cirrhotic liver (3). It is for this reason that the value for hepatic blood flow is referred to as estimated hepatic blood flow. However, both factors of extrahepatic BSP removal and non-uniform BSP ex- traction should operate to the same extent in any individual before and after portacaval anastomosis. Hence, every effort was made to make measurements under the same conditions and with the catheter at the same sampling site in the liver.

Measurements of EHBF were made on two separate occasions prior to portacaval anastomosis in two patients (P.N. and P. P.), in one of whom (P. N.) the values were obtained before and after an unsuccessful attempt to establish a shunt. Although an anomalous portal vein was ligated and transected at the first operation, EHBF changed from 1,220 to $1,890 \mathrm{ml}$. per minute and then fell to $880 \mathrm{ml}$. per minute following the second operation. It may be concluded that portal venous blood continued to perfuse the liver in P. N. under high pressure until completion of the shunting procedure. In P. P., EHBF, determined four and two months pre-operatively, amounted to 960 and $1,080 \mathrm{ml}$. per minute. Unfortunately additional data of this kind were not obtainable but it seems unlikely that spontaneous changes in EHBF can account entirely for the alteration following portacaval anastomosis.

\section{Hepatic extraction of bromsulfalein}

In association with the fall in EHBF the hepatic extraction of bromsulfalein $\left(\mathrm{E}_{\mathrm{BSP}}\right.$ ) increased in six patients and remained relatively unchanged in four (P. McC., N. D., T. K. and E. K., Table I).

TABLE III

Arterial-portal venous oxygen concentration difference in cirrhosis*

\begin{tabular}{|c|c|c|c|c|}
\hline \multirow[b]{2}{*}{ Subject } & \multirow[b]{2}{*}{ Vein } & \multicolumn{2}{|c|}{ Oxygen concentration } & \multirow{2}{*}{$\begin{array}{l}\text { Arterial-portal } \\
\text { venous oxygen } \\
\text { difference }\end{array}$} \\
\hline & & Arterial & $\begin{array}{l}\text { Portal } \\
\text { venous }\end{array}$ & \\
\hline \multirow[t]{2}{*}{$\begin{array}{ll}\text { E. K. } & \text { (1) } \\
\text { L. M. } & \text { (3) } \\
\text { F. N. } & \text { (2) } \\
\text { M. S. } & \text { (3) } \\
\text { M. N. } & \text { (3) } \\
\text { S. M. } & \text { (3) } \\
\text { H. C. } & \text { (3) } \\
\text { D. P. } & \text { (2) } \\
\text { M. M. } & \text { (3) } \\
\text { C. McC. (3) } \\
\text { J. L. } & \text { (1) }\end{array}$} & $\begin{array}{l}\text { Gas. } \\
\text { Inf. } \\
\text { Gas. } \\
\text { Mid. } \\
\text { Inf. } \\
\text { Inf. } \\
\text { Inf. } \\
\text { Mid. } \\
\text { Inf. } \\
\text { Inf. } \\
\text { Gas. }\end{array}$ & \begin{tabular}{|c|}
$m l . \%$ \\
13.3 \\
16.5 \\
13.3 \\
13.0 \\
14.9 \\
14.1 \\
15.5 \\
11.0 \\
16.7 \\
13.9 \\
14.5
\end{tabular} & $\begin{array}{r}\text { ml. \% } \\
9.9 \\
13.3 \\
10.5 \\
10.7 \\
12.9 \\
12.3 \\
14.0 \\
9.6 \\
15.3 \\
12.7 \\
13.5\end{array}$ & $\begin{array}{l}\text { ml. \% } \\
3.4 \\
3.2 \\
2.8 \\
2.3 \\
2.0 \\
1.8 \\
1.5 \\
1.4 \\
1.4 \\
1.1 \\
1.0\end{array}$ \\
\hline & & & & $\begin{array}{c}2.0 \\
\pm 0.79\end{array}$ \\
\hline
\end{tabular}

* Portal venous blood was sampled one to three days following portacaval anastomosis [(1) end-to-side, (2) sideto-side, (3) spleno-renal] through a catheter left in place for regional heparinization in the gastroepiploic vein (Gas.), inferior mesenteric vein (Inf.), or the midcolic vein (Mid.). 
On the average $E_{B S P}$ rose from $26.5 \pm 12.9$ per cent to $42.9 \pm 12.5$ per cent, a highly significant change (dev./S.E. = 3.7).

Bromsulfalein extraction has been shown (11), in general, to vary inversely with the blood level in normal subjects and the same tendency was demonstrable in this series pre-operatively (Table I). In order to avoid changes in extraction attributable to a change in $\mathrm{P}_{\mathrm{BSP}}$ rather than blood flow and/or hepatocellular activity, an effort was made to make measurements at the same BSP concentration before and after operation. On the whole, this attempt was successful since $P_{\text {BSP }}$ changed greatly only in P. N. (1.5 to $0.81 \mathrm{mg}$. per cent) and E. K. (0.77 to $1.55 \mathrm{mg}$. per cent). Possibly the absence in change in $\mathrm{E}_{\mathrm{BSP}}$ in $\mathrm{E} . \mathrm{K}$. following operation may be attributed to the rise in $\mathrm{P}_{\mathrm{BSP}}$, and, contrariwise the magnitude of the change in $P$. N. may have been exaggerated by the fall in $\mathrm{P}_{\mathbf{B g P}}$. Values for $\mathrm{E}_{\mathrm{BSP}}$ in $\mathrm{P}$. N. determined on two occasions before the final successful portacaval anastomosis were 11 and 18 per cent at $P_{\text {BSP }}$ levels of 1.50 and $0.67 \mathrm{mg}$. per cent, respectively. (Also in $\mathrm{P}$. $\mathrm{P}$., the two preoperative control measurements yielded values for $E_{B S P}$ of 11 and 15 per cent at $P_{B S P}$ equal to 1.49 and $0.86 \mathrm{mg}$. per cent, respectively.) In the remainder of the subjects, any alteration in $E_{B \& P}$ after portacaval anastomosis may be considered to have occurred independently of a change in $P_{B S P}$.

The plasma concentration of BSP also tended to vary inversely with estimated hepatic blood flow pre-operatively (Table I). The plasma level of BSP is largely a function of the amount infused and the ability of the liver to eliminate it. In normal persons (3), 4 to $6 \mathrm{mg}$. of BSP must be infused each minute to maintain $P_{B s p}$ at levels equal to those attained in this investigation. The low infusion rate used here, indicated by the removal rate $\left(R_{B S P}\right.$-Table $\left.I\right)$, resulted in a low $P_{B S P}$ in those patients with relatively good function and in high values in those with a reduced capacity to remove the dye. Thus, the apparent inverse correlation between $\mathrm{P}_{\mathrm{BSP}}$ and $\mathrm{EHBF}$ may be regarded simply as the result of the variation in the degree of liver damage. This view is borne out by the sequel. Since the plasma levels were kept at approximately the same values after operation while EHBF and $\mathbf{E}_{\mathrm{BSP}}$ changed in opposite directions, the correlation was no longer demonstrable. Brom- sulfalein extraction presented much less percentage variation post-operatively despite the same range in $\mathrm{P}_{\mathbf{B S P}}$.

\section{Hepatic oxygen uptake}

The hepatic arteriovenous oxygen difference increased following portacaval anastomosis in 9 of the 12 patients in whom it was measured (Table II), increasing on the average in the group as a whole from $4.1 \pm 0.6$ to $5.8 \pm 1.5 \mathrm{ml}$. per $100 \mathrm{ml}$. blood. The difference between the pre-operative and post-operative values was statistically significant (dev./S.E. = 3.8). The change could be entirely accounted for by a fall in the oxygen content of hepatic venous blood. Possibly the shunt was not operating effectively in the two subjects (E. K. and K. O'D.) in whom the hepatic arteriovenous oxygen difference decreased, but this possibility cannot be substantiated on the basis of the available data. In P. N. and P. P., the hepatic arteriovenous oxygen difference changed from 4.2 to $3.6 \mathrm{ml}$. per $100 \mathrm{ml}$. blood, and from 4.9 to $6.1 \mathrm{ml}$. per $100 \mathrm{ml}$. blood, respectively, in the two control measurements made before portacaval anastomosis and in each it increased after the shunt had been established, to 6.8 and $8.4 \mathrm{ml}$. per $100 \mathrm{ml}$. blood, respectively.

Calculation of total "hepatic oxygen uptake" from simultaneously determined values for EHBF and hepatic arteriovenous oxygen difference yielded figures (average, $50.9 \pm 13.9 \mathrm{ml}$. per minute, Table II) which agreed with those obtained in other patients with cirrhosis (3). There was no significant change post-operatively indicating an inverse correlation between EHBF and hepatic arteriovenous oxygen difference. It must be emphasized that this calculation of the "hepatic oxygen consumption" provides at best an estimate of the true value. An undetermined volume of oxygen has been removed from the portal blood which contributes to the total hepatic venous outflow. In normal individuals the calculation presumably yields a value for total splanchnic oxygen consumption but in cirrhosis a significant and unmeasured proportion of the portal blood is diverted from the liver through collateral channels. Failure to correct for the lower oxygen content of portal venous blood results in falsely high values for the hepatic oxygen arteriovenous difference and for the hepatic oxygen uptake, whereas failure to allow for di- 
version gives rise to falsely low values for splanchnic oxygen consumption.

Measurement of the oxygen content of portal venous blood obtained in 11 patients (including two [E. K. and H. C.] in whom EHBF had been determined) revealed a relatively high concentration in resting patients. The arterial-portal vein oxygen difference averaged $2.0 \pm 0.79 \mathrm{ml}$. per $100 \mathrm{ml}$. blood (Table III). Hence the error introduced in the calculation of the hepatic oxygen consumption by the failure to correct for portal venous oxygen levels is probably small, particularly in patients with cirrhosis in whom portal flow contributes less to total hepatic blood flow than in normal persons.

\section{DISCUSSION}

Since portal venous pressure decreased in every instance at operation immediately after opening the portacaval shunt (see Addenda) it seems reasonable to attribute the fall in EHBF observed as long as two years post-operatively to a persistent reduction in portal venous pressure. The fall in EHBF may therefore be considered a reflection of diminished hepatic portal inflow modified to some extent perhaps by secondary changes in hepatic arteriolar resistance and hepatic arterial inflow. Such an interpretation is based upon the belief that portal hypertension is a consequence of increased resistance to flow through the portal venous system within the cirrhotic liver. Recent work $(12,13)$ suggests that this view may be inadequate.

Myers and Taylor (12) have found that the pressure in an hepatic venule measured through an occluding venous catheter averaged $4.8 \mathrm{~mm}$. $\mathrm{Hg}$ in normal persons and 20.1 (range 11.5 to 32 ) $\mathrm{mm}$. $\mathrm{Hg}$ in patients with cirrhosis. The gradient between the occluded venular pressure and the free hepatic venous pressure was small in the nor$\mathrm{mal}$ ( $3.3 \mathrm{~mm}$. $\mathrm{Hg}$ on the average) and elevated in the cirrhotic (14.4 mm. $\mathrm{Hg}$ on the average). Since the catheter is extended, in effect, by this technique to the nearest freely anastomosing vascular system, the occluded hepatic venular pressure is apparently a measure of sinusoidal pressure. The increased hepatic venous-sinusoidal pressure gradient and the reduced hepatic blood flow in cirrhosis may therefore be interpreted as evidence for increased resistance to flow in the post-sinusoidal vasculature. The similarity between sinusoidal and portal venous pressures under these circumstances may mean that the portal venular resistance is not greatly increased or (what is more likely) that portal venous inflow is very greatly reduced. Kelty, Baggenstoss, and Butt (13) have brought forward anatomical evidence that the vascular resistance in the post-sinusoidal vascular bed is increased in cirrhosis. Moreover, arteriovenous communications between the radicles of the portal vein and the hepatic artery appear in the cirrhotic liver (14).

These facts lend some credibility to the notion that arterial blood may actually perfuse the portal vein in a retrograde manner in cirrhosis, accounting in part for the elevation in portal venous pressure. If this were the case, the fall in portal venous pressure following portacaval anastomosis might actually give rise to augmented hepatic arterial inflow with diminished hepatic venous outflow resulting from a concurrent fall in sinusoidal pressure. Even if retrograde flow did not occur as a rule, it might develop following portacaval anastomosis, at least transiently.

The fall in EHBF observed in three patients (P. McC., N. D., and E. K.-39, 21, and 47 per cent, respectively) following end-to-side portacaval anastomosis is clearly opposed to this view. Since the portal vein is ligated in an end-to-side anastomosis the change in EHBF can only be ascribed to the cessation of portal venous inflow in these patients. If retrograde flow of blood through the portal vein were important one would expect portal venous ligation to have no effect on EHBF or to augment it. It may be concluded that portal venous hypertension plays an important role in maintaining hepatic portal flow in cirrhosis. Although measurements of venous pressure must be made by Myers' technique (12) before and after operation it seems likely that the decrement in EHBF bespeaks a proportional fall in sinusoidal pressure suggesting the possibility that portal venous pressure (or splenic, gastric, mesenteric, and colic arterial inflow) is a major determinant of pressure in the sinusoids.

The constancy of hepatic oxygen consumption despite slowed perfusion and diminished delivery of oxygen accounts for the elevation observed in hepatic arteriovenous oxygen difference. Since the oxygen content of hepatic venous blood de- 
creased it may be inferred that tissues served by the terminal portions of the vasculature were subjected to a lower oxygen tension, but this state of relative hypoxia does not seem to have been detrimental. In fact, bromsulfalein extraction increased and the total removal or clearance of the dye was little affected on the average. More prolonged contact between hepatic cells and the blood apparently permitted more effective BSP uptake.

Laennec's cirrhosis is characterized ( 3 ) by a marked reduction in total BSP removal without much change in hepatic oxygen consumption from normal, as noted in the subjects of this study (Table I). This disparity might be explained on the basis of augmented oxidative activity by the diminished mass of residual functioning tissue with a secondary depression in BSP uptake. Or BSP excretion may be impaired as the result of a defect in bile formation secondary to loss of lobular pattern and distortion of the biliary drainage tract, without change in oxygen consumption because the cells continue their oxidative activities though no longer properly integrated to form an effective excretory system. The effect of portacaval anastomosis appears to conform with the latter hypothesis because BSP extraction would not be expected to rise in company with increased oxygen extraction if these two cellular activities were inversely related on some functional or competitive basis. In any case, it seems likely that the oxygen consumption of the reduced mass of functional tissue must be somewhat increased, though in the absence of a measure of functional tissue mass it is impossible to put this concept on a sound footing. For the same reason the problem of the relative perfusion rate cannot be solved at present since, on the one hand, EHBF is increased relative to BSP removal, suggesting hyperemia and, upon the other, it is diminished relative to oxygen consumption, suggesting ischemia of hepatic tissues.

The absence of a significant reduction in estimated hepatic oxygen consumption appears to indicate that relatively little oxygen is removed from the portal venous blood by extrahepatic tissues and measurement of the portal venous oxygen content bears out this interpretation. It could be argued that the small difference between arterial and portal venous oxygen concentrations, noted in this and other studies $(15,16)$, indicates retrograde flow of hepatic arterial blood into the portal system. The fact that the highest value (E. K., $3.4 \mathrm{ml}$. per $100 \mathrm{ml}$. blood-Table III) was obtained in a patient who had undergone end-to-side portacaval anastomosis with ligation of the portal vein could be brought forward to support such a thesis. However, in the only other person in whom portal venous oxygen content was measured following an end-to-side portacaval shunt, the arteriovenous difference was quite low (J. L., $1.0 \mathrm{ml}$. per $100 \mathrm{ml}$. blood). It is more likely that reflux of blood from the inferior vena cava occurred in E. K. during sampling, giving rise to a falsely low value for portal venous oxygen content. Hence it may be concluded that a substantial portion of the oxygen supply to the liver is derived from the portal venous inflow in cirrhosis. But since portal flow makes up only one-quarter of the total blood flow through the liver (if the decrement in EHBF is a measure of the portal contribution) it is evident that the hepatic arterial inflow accounts for a major portion of the liver's oxygen supply. Ligation of the hepatic artery in cirrhotic patients to lower portal venous pressure may therefore critically reduce the delivery of oxygen to hepatic tissues.

Although quantitative evaluation of the hemodynamic factors controlling blood flow through the cirrhotic liver is not feasible at present, owing to lack of information regarding simultaneous pressures and rates of flow in the different components of the splanchnic vasculature, a provisional qualitative appraisal seems permissible. The hepatic blood flow appears to be reduced in cirrhotic disease solely as a result of interference with portal venous inflow, presumably as a result of increased resistance to flow through both portal and hepatic venules. Hepatic arterial inflow does not increase sufficiently, if it changes at all, to compensate for this defect. The hemodynamic changes in cirrhosis appear to be of secondary rather than primary importance, since the exaggeration of the fundamental circulatory derangement following portacaval anastomosis does not appear to intensify or accelerate the underlying disease process.

\section{SUM MARY}

1. Estimated hepatic blood was measured by the bromsulfalein method in 10 patients with cirrhotic disease and hepatic arteriovenous oxygen difference in 12, before and after establishment of a portacaval shunt (end-to-side portacaval anastomosis 
in three, side-to-side portacaval anastomosis in two, and by end-to-side splenorenal venous anastomosis in five). The oxygen content was determined in portal venous blood withdrawn several days postoperatively through a catheter left in place for regional heparinization in 12 patients.

2. Estimated hepatic blood flow (EHBF) decreased following anastomosis in every instance, from $1,266 \pm 282 \mathrm{ml}$. per minute to $845 \pm 284$ ml. per minute on the average, a highly significant difference. Bromsulfalein extraction increased in six and remained relatively unchanged in four patients, changing significantly on the average from $26.5 \pm 12.9$ per cent to $42.9 \pm 12.5$ per cent. The hepatic arteriovenous oxygen difference increased in 9 of 12 subjects, from $4.1 \pm 0.6$ to $5.8 \pm$ $1.5 \mathrm{ml}$. per $100 \mathrm{ml}$. blood on the average. Although mean hepatic arteriovenous oxygen difference increased significantly, estimated hepatic oxygen consumption was not affected. The arterialportal venous oxygen difference ranged from 1.1 to $3.4 \mathrm{ml}$. per $100 \mathrm{ml}$. blood and averaged $2.0 \pm$ 0.79 .

3. The fall in hepatic blood flow post-operatively is apparently attributable to diversion of portal venous blood from the liver directly into the systemic venous system. The slower perfusion of the liver without significant change in total oxygen consumption and BSP removal by the liver resulted in augmented extraction of oxygen and BSP.

\section{ADDENDA}

\section{Case reports}

A. R. (P. H. No. 988832) is a white man, 54 years of age, in good health until the sudden onset of a massive hematemesis in May 1948, which necessitated hospitalization and transfusions. He was well thereafter until March 1949 when melena developed. Esophageal varices were demonstrated by X-ray at that time. A second hematemesis resulted in hospitalization on 13 March 1950. There was no evidence of previous jaundice, hepatitis, exposure to hepatotoxins, or excessive intake of alcohol. Hepatosplenomegaly and hemorrhoids were discovered on physical examination. The laboratory studies revealed the following: Thrombocytopenia (platelet count 68,000 ); serum bilirubin, faint trace; alkaline phosphatase, 2.7 B.U.; cholesterol, $192 \mathrm{mg}$. per cent (48.5 per cent esters); serum protein, $7.2 \mathrm{gm}$. per cent $(\mathrm{A} / \mathrm{G}-4.3 / 2.9)$, cephalincholesterol flocculation and thymol turbidity, $3+$; and BSP retention of 25 per cent after 30 minutes. Hepatic function studies reported above (Tables I and II) were made on 27 March 1950. At operation, on 4 April 1950, an enlarged, hard, and nodular liver was found. Biopsy revealed distortion of the hepatic architecture by bands of fibrous tissue connecting the portal spaces and central veins, infiltration with lymphocytes, and slight proliferation of the bile ducts. A side-to-side anastomosis was made between the portal vein and inferior vena cava, with a fall in portal venous pressure from 360 to $40 \mathrm{~mm}$. saline. Convalescence was uneventful and the hepatic function studies (Tables I and II) were repeated on 17 April 1950. There was no change in the laboratory findings postoperatively other than a rise in the platelet count to 125,000 . He continued to complain of weakness and faintness and became icteric in February 1951 (bilirubin, $2.0 \mathrm{mg}$. per cent) but this cleared spontaneously. He was rehospitalized on 2 April 1952 for study of signs of mental deterioration evident in slurred speech and hallucinations. Esophageal varices could not be detected by X-ray.

P. P. (P. H. No. 921721), a Negro, 22 years of age, suffered a bout of "infectious hepatitis" in 1945 while in the British Army. Jaundice, bilinuria, intolerance to fatty foods, intermittent pruritus and light colored stools persisted thereafter. Hepatosplenomegaly was discovered in May 1946. An episode of melena and syncope occurred in October 1946 followed by hospitalization for a six months period and discharge from the Army. There were three recurrences of melena and jaundice in 1947 and 1948. He denied exposure to hepatotoxins or excessive intake of alcohol. Following admission to the hospital on 21 September 1948, hepatosplenomegaly was noted. The laboratory study revealed an elevated serum bilirubin (1.9 mg. per cent) ; alkaline phosphatase 20.7 B.U.; cholesterol, 328 mg. per cent (71 per cent esters); serum protein, $7.4 \mathrm{gm}$. per cent (A/G-4.9/2.5) ; cephalin-cholesterol flocculation, negative; thymol turbidity, $2+$; and BSP retention of 45 per cent in 30 minutes. There was no evidence of esophageal varices by $\mathrm{X}$-ray. The hepatic function studies described above (Tables I and II) were made on 1 November 1948. At operation, 7 November 1948, the liver was slightly enlarged and nodular. Biopsy revealed a minimal increase in portal connective tissue and slight proliferation of the small bile ducts, but no bile plugs were seen. Owing to difficulty in isolating the portal vein (pressure $-460 \mathrm{~mm}$. saline) no attempt was made to establish an anastomosis. The portal vein, which was partially thrombosed, was ligated and the gall-bladder, thickened, edematous and containing one small stone, was removed. Convalescence was complicated by the accumulation of bile-stained ascitic fluid. A second hepatic venous catheterization for studies of hepatic functions was carried out on 31 December 1948. A splenorenal anastomosis was established on 1 February 1949; portal venous pressure changed very little, 260 to $240 \mathrm{~mm}$. saline. Convalescence was complicated by ileus but was otherwise satisfactory. A third hepatic venous catheterization was performed on 23 February 1949 (Tables I and II). Laboratory studies in June 1949 revealed clearing of jaundice; serum protein, $8.3 \mathrm{gm}$. per cent (A/G-4.9/3.4); negative cephalin-cholesterol flocculation and thymol 
turbidity; and no change otherwise. $\mathrm{He}$ was well until 15 May 1951 when he was hospitalized following hematemesis. There was no change in liver function at this time but esophageal varices were found on $\mathrm{X}$-ray examination. He recovered uneventfully following transfusion and has been well to date (April 1952).

K. N. (P. H. No. 867335), a 38 year old white woman, was hospitalized on 16 September 1947 with a story of persistent ascites of three years' duration. Her illness began insidiously with recurrent cramping right upper quadrant pain radiating to the midline. After two months, ascites appeared in association with anorexia, weakness, jaundice, light-colored stools and dark urine. All these manifestations cleared slowly but the ascites remained resistant to therapy, which included insertion of a peritoneal "button" on two occasions. Paracentesis was necessary at approximately two-week intervals during the year prior to admission. Despite a good appetite and adequate diet she lost weight steadily and hypoproteinemia developed. Physical examination revealed only "liver palms," ascites, and edema of the lower extremities. The laboratory study revealed the following: serum bilirubin, faint trace; alkaline phosphatase, 16.2 B. U.; cholesterol, $240 \mathrm{mg}$. per cent (71 per cent esters) ; serum protein, 5.9 gm. per cent (A/G-3.7/2.2); cephalin-cholesterol flocculation, 3+; and BSP retention of 25 per cent after 30 minutes. $\mathrm{X}$-ray examination revealed several opaque shadows in the cystic duct, but esophageal varices were not demonstrable. The hepatic function studies described above (Tables I and II) were made on 22 September 1947. At operation on 10 October 1947 a "hobnail" liver and an enlarged spleen were found. After splenectomy, an end-to-side anastomosis was made between the splenic and left renal vein; the portal venous pressure fell from 210 to $200 \mathrm{~mm}$. saline. She recovered uneventfully and within four months all the abnormalities noted in the laboratory study had cleared. Ascites did not recur after one month, and she gained more than 30 pounds in the next year. Measurements of EHBF and hepatic oxygen uptake (Tables I and II) were repeated on 21 April 1950. She was readmitted on 31 January 1952 because of bouts of right upper quadrant pain and increasing intolerance to fatty foods. A gall bladder containing three small calculi was removed on 6 February 1952. The liver was small, nodular and soft; the portal venous system was "collapsed." Microscopic examination of the liver tissue disclosed bands of connective tissue connecting the portal areas and accentuating the lobular pattern. She recovered uneventfully and has returned to full activity.

P. McC. (P.H. No. 950519), a 23 year old white man, was hospitalized on 25 November 1949, complaining of repeated hematemeses during the past five years. The first episode occurred in 1944 following a blow to the abdomen. Hospitalization and study at this time revealed no apparent cause but an enlarged spleen was discovered following a second massive hematemesis one year later (1945) and splenectomy was performed. The liver was described as "moderately cirrhotic." Hematemesis recurred on more than five occasions thereafter, requiring repeated transfusions. Esophagoscopy (1948) revealed large esophageal varices which were injected with a sclerosing solution without affecting the course. There was no evidence in the history of jaundice, exposure to hepatotoxins or excessive intake of alcohol. The physical examination revealed no obvious abnormality. The laboratory findings were as follows : serum bilirubin, $1.0 \mathrm{mg}$. per cent; alkaline phosphatase, 4.0 B.U.; cholesterol, $285 \mathrm{mg}$. per cent ( 77 per cent esters) ; serum protein, $7.6 \mathrm{gm}$. per cent (A/G-4.9/2.7) ; negative cephalin-cholesterol flocculation and thymol turbidity; and normal BSP retention. $\mathrm{X}$-ray examination revealed unusually large esophageal varices. The hepatic function studies described above (Tables I and II) were made on 23 November 1949. At operation on 29 November 1949 the liver was somewhat irregular in shape and smaller than normal and the portal vein was partially occluded by an old well-organized thrombus. An end-to-side anastomosis was made between the portal vein and the inferior vena cava, the portal pressure decreased from 620 to $540 \mathrm{~mm}$. saline after the shunt was opened. Biopsy of the liver revealed thickening of the capsule, moderate distortion of the parenchymal architecture by bands of connective tissue extending between the portal spaces. Convalescence was complicated by several hematemeses which ceased following cauterization of an ulcer of the nasal septum. The hepatic function studies were repeated (Tables I and II) on 6 February 1950. He remained well thereafter and $\mathrm{X}$-ray study revealed marked diminution in the size of the esophageal varices in December 1949. However, on 16 April 1951 he suffered a small hematemesis.

P.N. (P. H. No. 920839) is a 20 year old white man, hospitalized on 14 October 1948. Splenomegaly was discovered at the age of 10 during a bout of nausea and abdominal pain. He remained in good health thereafter until December 1947 when these symptoms recurred. He was hospitalized for several months and splenectomy was attempted unsuccessfully. He was transferred to Presbyterian Hospital following a second hospitalization in September 1948 because of a hematemesis. A history of hepatitis, jaundice or excessive intake of alcohol was denied. On admission, a large, smooth slightly tender mass was palpable in the left upper quadrant, the liver edge was just palpable, non-tender, and of normal consistericy. Laboratory studies revealed the following: platelet count, 96,000 ; serum bilirubin, $0.6 \mathrm{mg}$. per cent; alkaline phosphatase, 12.5 B.U.; cholesterol, $167 \mathrm{mg}$. per cent; serum protein $5.5 \mathrm{gm}$. per cent (A/G-4.4/1.1); negative cephalin-cholesterol flocculation and thymol turbidity; 30 per cent retention of BSP after 30 minutes; and guaiac positive stools. $\mathrm{X}$-ray examination revealed esophageal varices. Hepatic function studies described above (Tables I and II) were made on 27 October 1948. An attempt to establish a portacaval anastomosis on 5 November 1948 was unsuccessful owing to extensive fibrous adhesions. A large anomalous portal vein was ligated and transected and a cholecystectomy was performed. Biopsy of the liver revealed a marked increase in connective tissue in the periportal areas with distortion of the lobules, proliferation of the bile ducts epithelium and moderate lymphocytic and plasma cell infiltration of the portal region. 
The post-operative course was complicated by the development of a biliary fistula, right radial nerve palsy, pleural effusion and hematemesis on one occasion. A second hepatic venous catheterization to permit measurement of EHBF and hepatic oxygen uptake was carried out on 15 December 1948. A splenectomy and end-to-side splenorenal venous anastomosis were successfully performed on 4 January 1949. The splenic venous pressure fell from 290 to $190 \mathrm{~mm}$. saline after the shunt was opened. Convalescence was uneventful, and a third study of hepatic function by the catheterization technique was made postoperatively on 21 January 1949 (Tables I and II). Laboratory studies at this time revealed: platelets, 324,000; alkaline phosphatase, 10.5 B.U.; serum protein, $6.4 \mathrm{gm}$. per cent $(\mathrm{A} / \mathrm{G}-3.5 / 2.9)$; cephalin-cholesterol flocculation, $2+$; thymol turbidity, negative; and BSP retention of 8 per cent after 30 minutes. X-ray revealed diminution of the esophageal varices. Since discharge he has presented no evidence of portal hypertension, but he began to drink heavily and he is now hospitalized at the Binghamton State Hospital for the Insane.

N. D. (P.H. No. 977618), a 32 year old white man, was admitted on 17 January 1950. Episodes of fever and jaundice occurred at the age of 18,25 , and 26 . Two months prior to admission he vomited a large quantity of blood. Hepatosplenomegaly and esophageal varices were discovered at this time. "Spider" angiomata were noted following admission. Laboratory study yielded the following data: serum bilirubin, $1.2 \mathrm{mg}$. per cent; alkaline phosphatase, 2.5 B.U.; cholesterol, $117 \mathrm{mg}$. per cent (72 per cent esters) ; serum protein, $7.5 \mathrm{gm}$. per cent (A/G4.0/3.5); cephalin-cholesterol flocculation and thymol turbidity, $3+$; and BSP retention of 51 per cent after 30 minutes. Hepatic function studies described above (Tables I and II) were made on 20 Jaunary 1950 . At operation, 24 January 1950, the liver was grossly enlarged, finely granular, and hard. Biopsy revealed nodular distortion of the parenchyma by fibrous vascular septa, lymphocytic infiltration and marked proliferation of the bile ducts. Following a side-to-side portacaval anastomosis the portal venous pressure fell from 490 to $160 \mathrm{~mm}$. saline. Convalescence was complicated by jaundice (bilirubin, $2.5 \mathrm{mg}$. per cent) but no other change. Post-operative determinations of EHBF and oxygen uptake (Tables I and II) were performed on 3 February 1950 . He remained well (except for persistent jaundice) until April 1951 when he suffered a bout of acute upper abdominal pain associated with elevated serum amylase apparently attributable to acute pancreatitis which responded satisfactorily to conservative management. He has shown no further change since that episode and remains jaundiced.

S. W. (P.H. No. 028158), a 28 year old white man, was hospitalized on 8 January 1951. His present illness began abruptly with hematemesis in January 1950, followed by an episode of melena in September 1950. On this occasion he was explored for possible peptic ulcer and hepatosplenomegaly was discovered. Melena recurred on the day of admission. He denied exposure to hepatotoxic agents, excessive intake of alcohol, jaundice or hepatitis. A left nephrectomy was performed in 1938 for pyonephrosis. Laboratory study yielded the following data : platelet count 40,000 ; serum bilirubin, trace; alkalin phosphatase, 3.2 B.U.; cholesterol, $174 \mathrm{mg}$. per cent (70 per cent esters); serum protein, $6.9 \mathrm{gm}$. per cent (A/G-4.1/2.8); negative cephalin-cholesterol flocculation and thymol turbidity; and no retention of BSP after 30 minutes. X-ray examination revealed esophageal varices. Hepatic functions described above (Tables I and II) were measured on 8 January 1951. Following a side-to-side portacaval anastomosis on 1 February 1951, the portal venous pressure fell from 300 to $100 \mathrm{~mm}$. saline. The liver was enlarged and hard, microscopic examination revealed marked distortion of the architecture by anastomosing fibrous cords. Convalescence was uneventful and hepatic function studies (Tables I and II) were repeated post-operatively on 16 February 1951 . Hematemesis recurred in December 1951 and a splenectomy was performed on 15 January 1952 . No varices were demonstrable at that time. Following splenectomy pancytopenia and thrombocytopenia cleared. In May 1952 a febrile illness, complicated by hematemesis and by development of pyuria, cleared on conservative therapy. $\mathrm{He}$ has remained fairly well since that time though there is evidence of mental deterioration.

H. C. (P.H. No. 027940) a 24 year old white man, was admitted on 1 January 1951. He had been well until the sudden onset of melena followed by the appearance of ascites and ankle edema in August 1950. He responded to transfusions and conservative dietary management, but melena recurred early in December 1950 . X-ray examination at this time disclosed esophageal varices. A past history of exposure to hepatotoxins, excessive use of alcohol, jaundice or hepatitis was denied. Hepatosplenomegaly and ascites without peripheral edema were noted on admission. Laboratory study revealed: serum bilirubin, faint trace; alkaline phosphatase, 5.7 B.U.; cholesterol, $168 \mathrm{mg}$. per cent (67 per cent esters); serum protein, $7.2 \mathrm{gm}$. per cent (A/G-4.9/2.3), negative cephalincholesterol and thymol turbidity; and 5 per cent BSP retention after 30 minutes. Hepatic venous catheterization was carried out on 5 January 1951 (Tables I and II). Following an end-to-side splenorenal venous anastomosis on 20 January 1951 the portal venous pressure fell from 250 to $130 \mathrm{~mm}$. saline. The liver was slightly nodular and firm, and microscopic examination revealed a slight increase in fibrous tissue. Convalescence was uneventful and a post-operative catheterization was performed on 20 January 1951 (Tables I and II). The esophageal varices seemed to decrease in size, but no other noteworthy post-operative change occurred.

T. K. (P.H. No. 931114), a 24 year old white man, was admitted on 11 November 1947 with a story of excessive alcoholic intake since the age of 16 , frequent epistaxes of five years' duration, splenomegaly of at least four years' duration and hematemeses on two occasions during the year prior to admission. Laboratory study yielded the following data: platelet count, 70,000; serum bilirubin, trace; alkaline phosphatase, 3.5 B.U.; cholesterol, $150 \mathrm{mg}$. per cent (72 per cent esters); serum protein, $8.0 \mathrm{gm}$. per cent (A/G-5.1/2.9) ; negative cephalin- 
cholesterol flocculation; thymol turbidity, $2+$; and 20 per cent BSP retention after 30 minutes. $\mathrm{X}$-ray examination revealed esophageal varices. Hepatic venous catheterization was carried out on 29 November 1948 (Tables I and II). Following an end-to-side splenorenal venous anastomosis on 14 December 1948 the portal venous pressure fell from 325 to $270 \mathrm{~mm}$. saline. The liver was grossly nodular and slightly enlarged; microscopic examination revealed slight portal fibrosis and lymphocytic infiltration. Convalescence was complicated by saphenous thrombophlebitis and recurrent left pleuritis with effusion. Post-operative hepatic function studies (Tables I and II) were made on 3 January 1949 . He has done well since discharge, the platelet count and thymol turbidity having returned to normal.

E. K. (P.H. No. 003783), a 55 year old white man, was admitted on 13 July 1950 with a story of excessive alcoholic intake for many years and of the sudden onset of melena and hematemesis in July 1949. Esophageal varices were injected with a sclerosing solution at this time but hematemesis recurred in April 1950. No history of jaundice or hepatitis was obtained. An enlarged liver and spleen were palpable on admission. Laboratory study revealed: platelet count, 86,000 ; serum bilirubin, $1.1 \mathrm{mg}$. per cent; alkaline phosphatase, 7.9 B.U.; cholesterol, 327 mg. per cent; serum protein, $7.3 \mathrm{gm}$. per cent (A/G4.2/3.1); cephalin-cholesterol flocculation and thymol turbidity, $3+$; and 29 per cent retention of BSP after 30 minutes. The spleen was removed on 23 July 1950 and portacaval anastomosis was deferred for technical reasons. Post-operatively the bilirubin concentration fell and the platelet count rose to 123,000 ; no other change occurred. Hepatic venous catheterization was carried out on 12 November 1950 (Tables I and II). Following an end-to-side portacaval anastomosis on 14 December 1950 the portal venous pressure fell from 580 to $220 \mathrm{~mm}$. saline. The liver was small, nodular, and firm; microscopic examination revealed bands of connective tissue dividing the parenchyma into variously sized lobules. Convalescence was uneventful and a post-operative hepatic venous catheterization was performed on 20 December 1950 (Tables I and II). Within a few months after operation the patient had returned to an active life and all abnormal laboratory findings had reverted to normal ( 7 May 1952).

C. M. (P.H. No. 917649), a 42 year old white man, was admitted on 24 July 1948 with a seven months' history of melena, jaundice, ascites, and hepatosplenomegaly. $\mathrm{He}$ denied excessive intake of alcohol or earlier episodes of jaundice or hepatitis. "Spider" angiomata and "liver palms" were noted on admission. Laboratory study revealed the following: serum bilirubin, $2.1 \mathrm{mg}$. per cent; alkaline phosphatase, 25.0 B.U.; cholesterol, $333 \mathrm{mg}$. per cent ( 50 per cent esters); serum protein, $7.5 \mathrm{gm}$. per cent (A/G-3.4/4.1) ; cephalin-cholesterol flocculation and thymol turbidity, $4+$; and 30 per cent BSP retention after 30 minutes. X-ray examination revealed esophageal varices. Hepatic venous catheterization was carried out on 11 October 1948 (Table II). An end-to-side portacaval anastomosis was established on 15 October 1948.
The liver was enlarged, finely nodular, and somewhat fatty in appearance; microscopic examination revealed diffuse fibrosis, lymphocytic infiltration, and replacement of parenchymal tissue. Hepatic venous catheterization was carried out on 29 October 1948 (Table II). There was no noteworthy change post-operatively. Frequent paracenteses were necessary to correct the persistent ascites and hypoalbuminemia required administration of concentrated human serum albumin. In March, 1949, esophageal varices could not be detected by $x$-ray but melena recurred in April with augmented jaundice that appeared to regress slowly under a short course of cortisone therapy. He continued to feel unwell and in May 1952 the sudden perforation of an anterior gastric ulcer necessitated surgical intervention. He continues to be jaundiced, esophageal varices are now demonstrable (May 1952) but ascites and edema have cleared completely. His chief complaints at present relate to peptic ulceration of the stomach and duodenum.

K.O'D. (P.H. No. 743312), a 19 year old white girl, was admitted on 15 February 1950 for elective splenectomy. At the age of five years she suffered a febrile illness and jaundice from which she seemed to recover completely. However, slight jaundice recurred from time to time in association with upper respiratory infections during the years that followed. In 1948 jaundice and ankle edema appeared and persisted. At this time hepatosplenomegaly and "spider" angiomata were noted. Laboratory study (January 1949) revealed the following: serum bilirubin, 3.7 mg. per cent; alkaline phosphatase, 14.9 B.U.; cholesterol, $183 \mathrm{mg}$. per cent ( 65 per cent esters); serum protein, $6.0 \mathrm{gm}$. per cent $(\mathrm{A} / \mathrm{G}-3.0 / 3.0)$; cephalin-cholesterol flocculation and thymol turbidity, $3+$; and 80 per cent retention of BSP after 30 minutes. Exploratory celiotomy (10 February 1949) revealed a grossly cirrhotic liver. She recovered from this procedure uneventfully but showed progression in further splenic enlargement, development of leucopenia and thrombocytopenia, increased alkaline phosphatase (17.0 B. U.), and anorexia, despite subsidence of edema. Hepatic venous catheterization was carried out on 21 February 1950 (Table II). On 7 March 1950 splenectomy followed by endto-side splenorenal venous anastomosis was performed. Biopsy of the liver at this time disclosed marked distortion of the parenchyma by broad bands of connective tissue containing many small bile ducts and lymphocytes. Convalescence was complicated by massive atelectasis of the right upper lobe. A second hepatic venous catheterization was performed on 13 October 1950 (Table II). She has done well since operation, the jaundice and edema having cleared completely. The cephalin-cholesterol flocculation is now negative but the serum cholesterol and alkaline phosphatase remain elevated. Bromsulfalein excretion is still greatly impaired. She has gained weight and feels well.

\section{ACKNOWLEDGMENTS}

We wish to express our gratitude to Mrs. Joan Banfield, Mrs. Lottie Klayman, and Mrs. Michaleen Patter- 
son for technical assistance, to Drs. William D. Blake, Preston Lowrance, James D. Nickel, and many others for professional aid, and to Dr. John Fertig for advice in the statistical analysis.

\section{REFERENCES}

1. Bradley, S. E., Macpherson, A. I., Gammeltoft, A., and Blakemore, A. H., Effect of portacaval anastomosis on hepatic oxygen extraction and estimated hepatic blood flow in patients with cirrhosis. J. Clin. Invest., 1951, 30, 630.

2. Smythe, C. McC., Fitzpatrick, H. F., and Blakemore, A. H., Studies of portal venous oxygen content in unanesthetized man. J. Clin. Invest., 1951, 30, 674.

3. Bradley, S. E., Ingelfinger, F. J., and Bradley, G. P., Hepatic circulation in cirrhosis of the liver. Circulation, 1952, 5, 419.

4. Whipple, A. O., The rationale of portacaval anastomosis. Bull. N. Y. Acad. Med., 1946, 2d ser., 22, 251.

5. Blakemore, A. H., Portacaval shunting for portal hypertension. Surg., Gynec. \& Obstet., 1952, 94, 443.

6. Bradley, S. E., Ingelfinger, F. J., Bradley, G. P., and Curry, J. J., The estimation of hepatic blood flow in man. J. Clin. Invest., 1945, 24, 890.

7. Blakemore, A. H., and Fitzpatrick, H. F., The surgical management of the postsplenectomy bleeder with extra-hepatic portal hypertension. Ann. Surg., 1951, 134, 420.
8. Van Slyke, D. D., and Neill, J. M., The determination of gases in the blood and other solutions by vacuum extraction and manometric measurement. I. J. Biol. Chem., 1924, 61, 523.

9. Bradley, S. E., Clinical aspects of hepatic vascular physiology. Tr. of the Ninth Conference on Liver Injury. Josiah Macy, Jr. Foundation, New York, 1950, p. 71.

10. Werner, A. Y., and Horvath, S. M., Bromsulphalein and cardiac output in hepatectomized dog. Federation Proc., 1952, 11, 170.

11. Bradley, S. E., Ingelfinger, F. J., and Bradley, G. P., Determinants of hepatic haemodynamics. Ciba Foundation Symposium on Visceral Circulation, J. \& A. Churchill, Ltd., London, 1952, pp. 219-232.

12. Myers, J. D., and Taylor, W. J., An estimation of portal venous pressure by occlusive catheterization of an hepatic venule. J. Clin. Invest., 1951, 30, 662.

13. Kelty, R. H., Baggenstoss, A. H., and Butt, H. R., The relation of the regenerated hepatic nodule to the vascular bed in cirrhosis. Proc. Staff Meet., Mayo Clin., 1950, 25, 17.

14. Popper, H., Elias, H., and Petty, D. E., Vascular pattern of the cirrhotic liver. Am. J. Clin. Path., 1952, 22, 717.

15. Sherlock, S., and Walshe, V., The use of a portal anastomotic vein for absorption studies in man. Clin. Sc., 1946, 6, 113.

16. Bean, W. B., Franklin, M., Embick, J. F., and Daum, $\mathrm{K}$, Absorption studies using portal anastomotic veins. J. Clin. Invest., 1951, 30, 263. 